\title{
Opinion \\ The times they are a-changing?
}

\author{
TIM SPARKS and HUMPHREY CRICK
}

For, lo, the winter is past, the rain is over and gone;

The flowers appear on the earth;

the time of the singing of birds is come,

and the voice of the turtle is heard in our land.

(Song of Solomon)

\section{Introduction}

It is clear from recent research that changes are occurring in the timing of many natural events. In most cases it is assumed that the changes, or most of them, are climate related, although associated changes in distribution, habitat quantity and quality, and population size must not be ignored. In this article we present our opinion that study of the timing of features of life cycles is vital in helping to predict the effects of climate change on wildlife. It represents cheap science and yet is extraordinarily good value, for money because it generally relies on geographically widespread networks of volunteer observers. The consequences of phenological changes are large and conservationists ignore them at the peril of the wildlife they seek to conserve.

\section{Background}

The timing of our seasons is popularly defined by biological activity rather than calendar date. The study of the timing of naturally recurring events is termed phenology and has a long history. For instance, in Japan traditional festivals were held in conjunction with the blossoming of cherry trees and the timing of some of these events back to the eighth century survives (Lauscher 1978). Similarly blossom dates from sixteenth century China survive (Hameed 1994). Within Europe recorded phenology has a shorter history, but is still of sufficient antiquity to produce records dating back 250 years (Sparks and Carey 1995).

Phenology, historically, has been associated with spring events such as the commencement of leafing and flowering of plants, the appearance of insects, the breeding activity of birds and other animals and so on. Given an economy almost totally reliant on agriculture this emphasis is not surprising. Spring, therefore, was a relief from the oppression of winter, a time for renewed agricultural activity and an opportunity for fresh food supplies for both humans and animals. However, phenology can and does apply more widely and can include autumn (fall) and other seasonal effects. 
It is now generally accepted within the scientific community that global climatic change will occur as a direct result of human activity (IPCC 1996). There is still some uncertainty as to the magnitude of change, the rate of change and how change will vary between regions. This uncertainty exists because extrapolation beyond current and past recorded conditions is necessary. The recent Kyoto agreement on carbon reduction would not seem to be stringent enough to slow change substantially. We can be reasonably assured, therefore, that we will experience change in climatic patterns over the next century. What we desire to know is how these changes will affect our native species. Initial thoughts suggest that species restricted to cooler latitudes might suffer as their habitat range contracts, and there might be a northwards shift in the distribution of other species. However, the pattern of change is likely to be much more complex than this due to differences in species' abilities to adapt to new conditions, differences in dispersal abilities and differences in competitive and trophic interactions under the new circumstances (Davis et al. 1998).

What then will be the consequences of climatic change for birds; their distribution, population and conservation status? Which species are at risk? Which can take advantage of changes? Possibly we shall not know before it is too late to take remedial action. We can set up models to examine effects, but can these ever cope with the complexities of the real world such as, for instance, the plethora of biotic and abiotic interactions? These interactions include synchrony, or lack of it, across trophic levels, effects of parasitism, desiccation, predation, land use and other human changes, food supplies and so on.

\section{Phenological data}

Recording pure phenology may be viewed harshly as an amateur activity but its value exceeds that associated with this scientific "put-down". Many phenological networks in Europe rely on amateurs and many recording schemes generally can only survive through the voluntary efforts of recorders who both enjoy their task and appreciate their contribution to monitoring and science. Phenological data can, in fact, be derived from many schemes for which they are not the primary objective. In the U.K. these include the British Trust for Ornithology's (BTO) Nest Record Scheme, the Butterfly Monitoring Scheme, the Rothamsted Insect Survey and the Continuous Plankton Recorder.

With the recent emphasis on climate change studies, those organizations that had the foresight to initiate monitoring schemes and the resolve to maintain them should be congratulated. They are the guardians of data that should allow us to investigate some of these complex interactions using past climatic events. The word "should" appears in this sentence for a number of reasons. First, cash, or lack of it, is the old enemy of scientific progress especially when the field is considered relatively unfashionable, does not involve any new "flashy" techniques, and money has to be committed for long periods. Second, the data necessary for investigations may exist across several organizations who may be protective of such data for a variety of reasons including funding, publication and status. Third, this is very much a multidisciplinary field but there are often insufficient links between, amongst others, climatologists, hydrologists, botanists, entomologists and ornithologists. Fourth, in some locations, we shall experience 
climates that have no current analogue and we have never experienced the forecast levels of $\mathrm{CO}_{2}$. Fifth, extreme events are forecast to become more frequent and the data may not exist to predict the consequences of two consecutive "extremes" on species, especially endangered species.

\section{Examples}

To illustrate some of the value of phenological data we show some examples from four independent data sets which display trends through time associated with climate responses.

- The UK Butterfly Monitoring Scheme (Pollard and Yates 1993). Weekly counts of butterflies are carried out on over 120 fixed-route transects. In each year, the week of peak abundance of the Green Hairstreak Callophrys rubi for each site has been determined, averaged over all sites where recorded and converted to a day number.

- Jean Combes's tree leafing records (Sparks et al. 1997). These consist of first leafing records of trees in Ashtead in Surrey, U.K. and Oak Quercus robur has been used as an example.

- The BTO's Nest Record Scheme (Crick and Baillie 1996) coordinates nesting data from across Britain and increases by c.35,000 individual nest records each year. For illustrative purposes the annual mean nesting date of Longtailed Tit Aegithalos caudatus has been used.

- Observation records of the spring arrival of migrants at British coastal bird observatories. For this example we have used the mean of the first observations of Blackcap Sylvia atricapilla from four observatories: Bardsey (Gwynedd), Calf of Man (Isle of Man), Dungeness (Kent) and Portland (Dorset). These data, means of four point estimates, are perhaps the least reliable of our examples, because the others are either national averages or static species. Potentially, data from over a dozen observatories could be available, but these are not yet computerized and coordinated.

We present data taken over the 30-year period 1966-1995, except for the butterfly, because that recording scheme only commenced in 1976. Figure 1 shows the timings of these variables with each horizontal division of the graph set at 10 days for clarity. All four species show a tendency for earliness in recent years. Some features are common to all graphs, for instance the late peak in 1986 for Long-tailed Tit appears also in the other three graphs. Other late (1970, 1979) and early (1990) peaks also seem to be common to the graphs, with the possible exception of the first observation date of Blackcaps.

In Figure 2 these same variables have been compared with Central England Temperatures (CET; Parker et al. 1992), which have been found to be a representative measure of temperature for much of the U.K. The Blackcap has been compared with March CET and the other three species with Mean February-April CET. All show significant regressions (Blackcap $r^{2}=21 \%, P<0.05$; Oak $r^{2}=58 \%$, $P<0.001$; Green Hairstreak $r^{2}=69 \%, P<0.001$; Long-tailed Tit $r^{2}=65 \%, P<$ 0.001 ). Whilst there may be some non-linearity to the relationships, the linear regression suggests a move towards earliness of $2.3,7.8,5.5$ and 4.1 days per additional degree Celsius, respectively. 

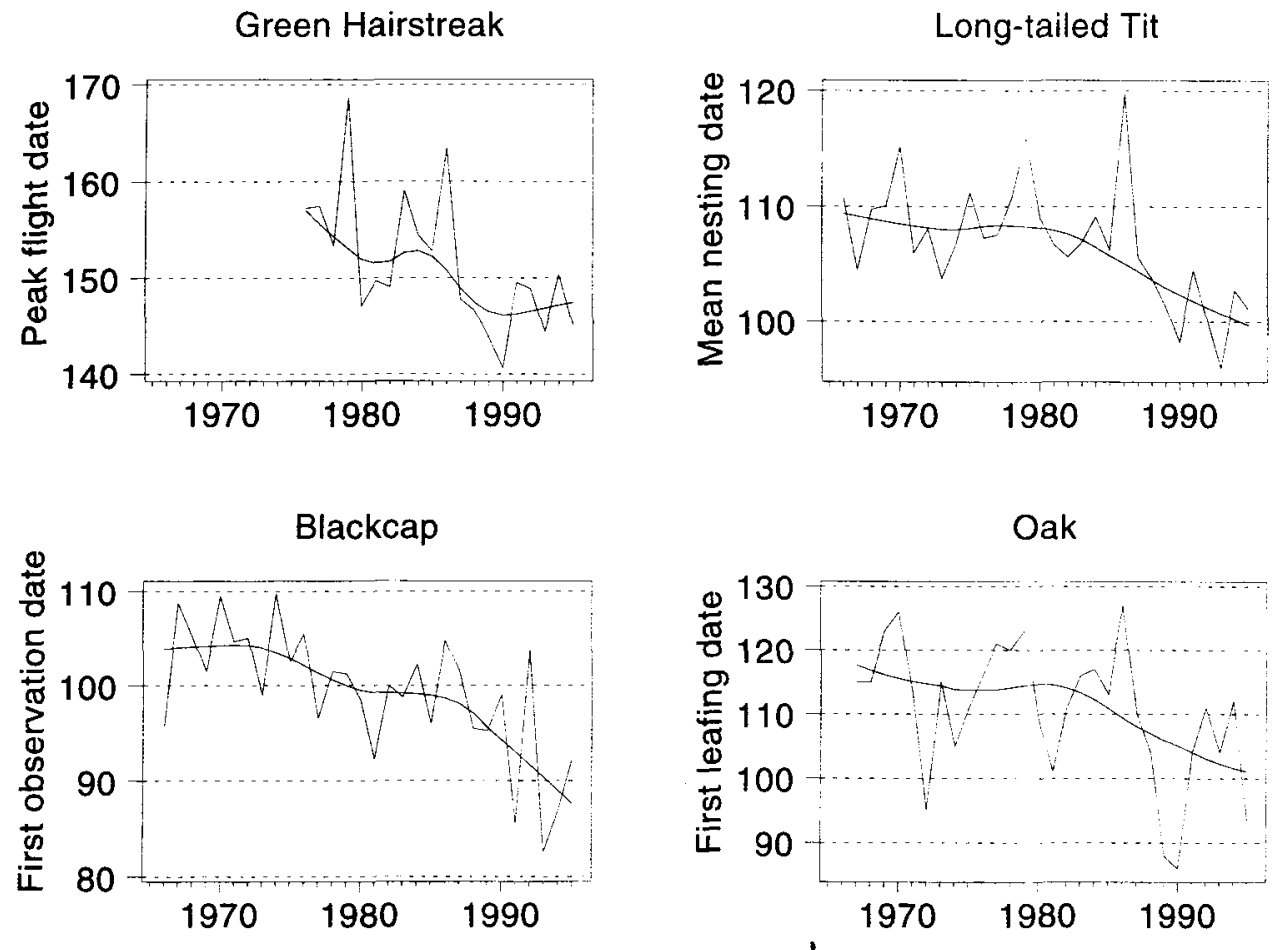

Figure 1. Trends in phenological time series for the period 1966-1995. A smoothed line has been superimposed. All dates are in days after December 31, thus in non-leap years day $91=$ April 1 , day $121=$ May 1 , day $152=$ June 1 , etc. See text for details.

\section{So what?}

Changes have been detected in the timings of a whole range of taxa and events (e.g. Beebee 1995, Fitter et al. 1995, Mason 1995, Crick et al. 1997, McCleery and Perrins 1998, Reid et al. 1998, Huin and Sparks 1998) and climatic effects have been implicated as the cause. By themselves these phenological changes may be considered merely of natural history interest, although enhanced knowledge of the response of species to climate is valuable. What we must do now is to see how changes in timing affect populations. These effects may be complex. On the positive side a longer season may lead to range expansion, increased brood numbers, increased fledging success, lower winter mortality, higher population levels. On the negative side there may be habitat changes, early desiccation of vegetation, increased parasitism, temporal asynchrony with food supplies. Perhaps most serious of all are the potential dangers of two "extreme" events in close succession.

In many cases the data to examine these population effects exist. However, it is usual to find that climatic, botanical, invertebrate and ornithological data are held by separate bodies. It is also usual to find that these data are not fully computerized and that there are no special measures to preserve older data. The reader will have noticed (and we apologize for) an obvious British bias to this paper which reflects our knowledge and experience. Experience suggests that it 

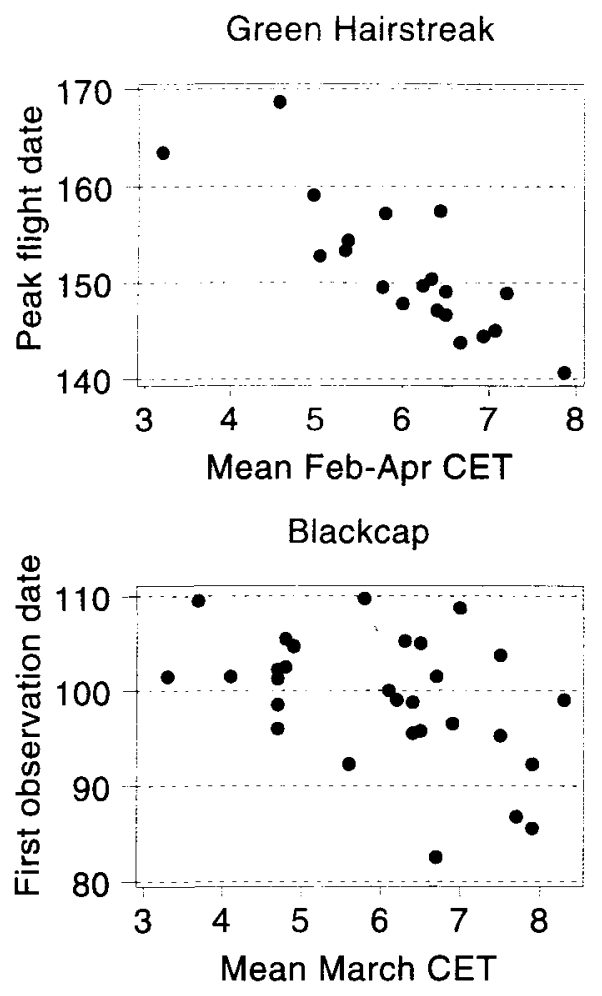
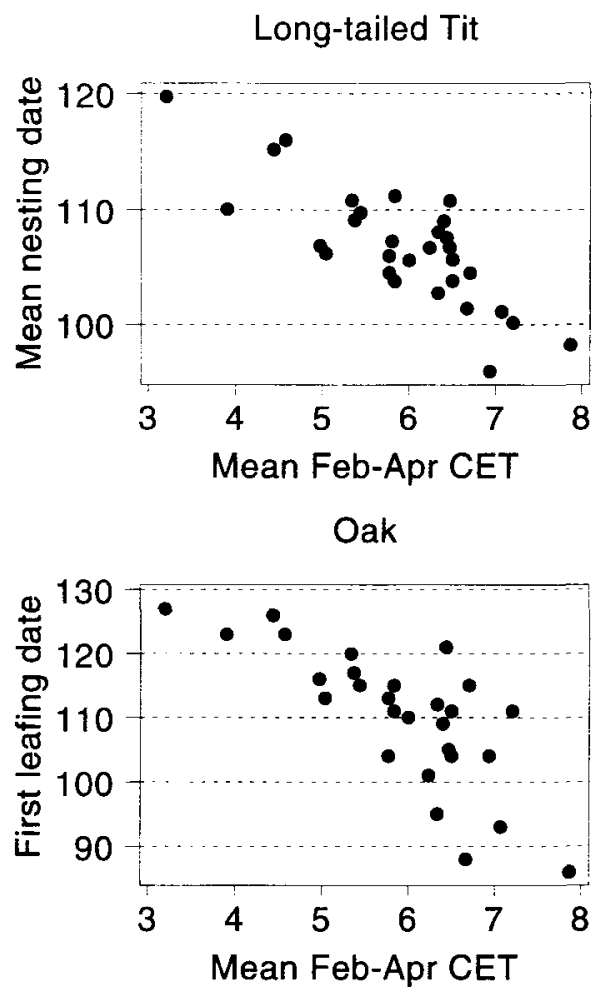

Figure 2. Relationships between phenological time series for the period 1966-1995. Dates in days after December 31 are related to Central England Temperature (CET). See text for details.

is not easy to find out what data exist on a continental or larger scale but we surmise that there will be very few long-term phenological data sets available for the tropics and southern hemisphere. Even on a national scale the phenological interests of forestry, horticultural, agricultural, hydrometeorological, university, marine, pest control, human health and conservation organizations may not be common knowledge.

\section{The way ahead?}

Whilst individual phenological records have little value in their own right, it is the temporal or spatial intensity of these records that makes them so potentially useful. Long time series from single locations and data with national (or international) coverage both have value. Oldham (1937) succinctly described the accumulated value of phenological records: "it is certain that observations, apparently trivial when viewed alone, will fall into their proper places when considered in connection with others, and go to the building up of an orderly and substantial structure". But the collection of data, by itself, is not enough. There needs to be a structure to the collection of data and, most important, a repository for those data so that they can be used for scientific research and not lost to the future. 
The value of phenological records across Europe was clearly demonstrated 60 years ago (Southern 1938a, b, 1939, 1940, 1941), but in terms of bird data there has been little or no continent-wide work since. In addition, phenological networks across Europe and elsewhere often concentrate on one trophic level without regard to others. Modifications to these systems in order to enhance their value must be considered. Finally we must ensure that there is sufficient interaction between the different disciplines to maximize the value of our collective data.

\section{The four Cs}

Our recommendations can be summarised as follows:

- "Curation" We need to identify what data already exist, seek out all other data, warts and all, before more data sets are lost. The value of historical data has already been proved.

- Computerization Data need to be easily available to be of most value; large amounts lie dormant and therefore of little use. We note that recognition of this issue is increasing. The U.K. Natural Environment Research Council has recently funded a thematic programme called SEEDCORN to computerize important data sets. The authors of this article have separately secured funding for the "data archaeology" of a U.K. historical phenology archive and for databasing the U.K. Heronries Census, which began in 1928 and is the longest running breeding bird census in Europe.

- Continuation Many organisations have struggled to maintain monitoring schemes without much help from those, externally, who pay lip-service that these constitute "gold-dust". These schemes must be preserved and enhanced where most appropriate. Such schemes are most at risk when their long-term protagonists retire from scientific research.

- Co-ordination We must increase coordination at a national and larger scale. In most cases the barrier to this is a fifth $\mathrm{C}$-Cash. For example, the computerization and coordination of British coastal bird observatory data requires a relatively modest capital input and international collaboration will reap rewards.

It is surprising that funding agencies have often failed to recognize that there are areas where big science can be achieved for small money. Phenological recording at large geographical scales represents a prime example of this opportunity.

\section{References}

Beebee, T.J.C. (1995) Amphibian breeding and climate. Nature 374: 219-220.

Crick, H.Q.P. and Baillie, S.R. (1996) A review of the BTO's Nest Record Scheme. Thetford, U.K.: British Trust for Ornithology.

Crick, H.Q.P, Dudley, C., Glue, D.E. and Thomson, D.L. (1997) UK birds are laying eggs earlier. Nature 388: 526.

Davis, A.J., Jenkinson, L.S., Lawton, J.H., Shorrocks, B. and Wood, S. (1998) Making mistakes when predicting shifts in species range in response to global warming. Nature 391: $783-786$.

Fitter, A.H., Fitter, R.S.R., Harris, I.T.B. and Williamson, M.H. (1995) Relationships 
between first flowering date and temperature in the flora of a locality in central England. Functional Ecol. 9: 55-60.

Hameed, S. (1994) Variation of spring climate in lower-middle Yangtse River Valley and its relation with solar-cycle length. Geophys. Res. Lett. 21: 2693-2696.

Huin, N. and Sparks, T.H. (1998) Arrival and progression of the swallow Hirundo rustica through Britain. Bird Study 45: 361-370.

IPCC (1996) Climate change 1995: the science of climate change. Cambridge, U.K.: Cambridge University Press.

Lauscher, F. (1978) Neue Analysen ältester und neuerer phänologischer Reihen. Arch. Meteorol. Geophysik Bioklimatol. B 28: 373-385.

Mason, C.F. (1995) Long̃term trends in the arrival dates of spring migrants. Bird Study 42: 182-189.

McCleery, R.H. and Perrins C.M. (1998) Temperature and egg-laying trends. Nature 391: 30-31.

Oldham, C. (1937) Migratory birds in Hertfordshire. A review of the annual reports in our transactions. Trans. Herts. Nat. Hist. Soc. Field Club 20: 141-150.

Parker, D.E., Legg, T.P. and Folland, C.K. (1992) A new daily Central England Temperature series, 1772-1991. Int. J. Climatol. 12: 317-342.

Pollard, E. and Yates, T.J. (1993) Monitoring butterflies for ecology and conservation. London, U.K.: Chapman and Hall.

Reid, P.C., Edwards, M., Hunt, H.G. and Warner, A.J. (1998) Phytoplankton change in the north Atlantic. Nature 391: 546.

Southern, H.N. (1938a) The spring migration of the swallow over Europe. British Birds 32: 4-7.

Southern, H.N. (1938b) The spring migration of the willow-warbler over Europe. Brit. Birds 32: 202-206.

Southern, H.N. (1939) The spring migration of the redstart over Europe. Brit. Birds 33: $34-38$.

Southern, H.N. (1940) The spring migration of the wood-warbler over Europe. Brit. Birds 34: 4-79.

Southern, H.N. (1941) The spring migration of the red-backed shrike over Europe. Brit. Birds 35: 114-119.

Sparks, T.H. and Carey, P.D. (1995) The responses of species to climate over two centuries: an analysis of the Marsham phenological record, 1736-1947. J. Ecol. 83: 321-329.

Sparks, T.H., Carey, P.D., and Combes, J. (1997) First leafing dates of trees in Surrey between 1947 and 1996. Lond. Nat. 76: 15-20.

\section{TIM SPARKS}

NERC Institute of Terrestrial Ecology, Monks Wood, Abbots Ripton, Huntingdon, Cambridgeshire PEI7 2LS, U.K.

email:t.sparks@ite.ac.uk

HUMPHREY CRICK

British Trust for Ornithology, The Nunnery, Nunnery Place, Thetford, Norfolk IP24 2 PU, U.K. email: h.crick@bto.org 